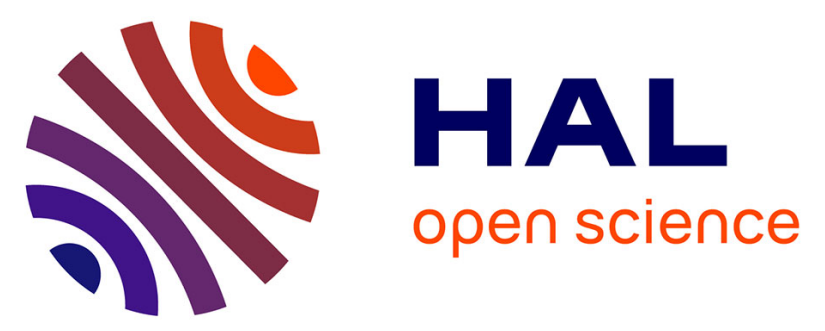

\title{
Acid-triggering of light-induced charge-separation in hybrid organic/inorganic molecular photoactive dyads for harnessing solar energy
}

Elisabetta Benazzi, Joshua Karlsson, Youssef Ben M'Barek, Pavel Chabera, Sébastien Blanchard, Sandra Alves, Anna Proust, Tönu Pullerits, Guillaume Izzet, Elizabeth A Gibson

\section{To cite this version:}

Elisabetta Benazzi, Joshua Karlsson, Youssef Ben M'Barek, Pavel Chabera, Sébastien Blanchard, et al.. Acid-triggering of light-induced charge-separation in hybrid organic/inorganic molecular photoactive dyads for harnessing solar energy. Inorganic Chemistry Frontiers, 2021, 10.1039/d0qi01368d . hal-03130031

\section{HAL Id: hal-03130031 \\ https: / hal.sorbonne-universite.fr/hal-03130031}

Submitted on 3 Feb 2021

HAL is a multi-disciplinary open access archive for the deposit and dissemination of scientific research documents, whether they are published or not. The documents may come from teaching and research institutions in France or abroad, or from public or private research centers.
L'archive ouverte pluridisciplinaire HAL, est destinée au dépôt et à la diffusion de documents scientifiques de niveau recherche, publiés ou non, émanant des établissements d'enseignement et de recherche français ou étrangers, des laboratoires publics ou privés. 


\title{
Acid-triggering of light-induced charge-separation in hybrid organic/inorganic molecular photoactive dyads for harnessing solar energy
}

Elisabetta Benazzi, ${ }^{a}$ Joshua Karlsson, ${ }^{a}$ Youssef Ben M'Barek, ${ }^{\mathrm{b}}$ Pavel Chabera, ${ }^{\mathrm{c}}$ Sébastien Blanchard, ${ }^{\mathrm{b}}$ Sandra Alves, ${ }^{b}$ Anna Proust, ${ }^{b}$ Tönu Pullerits, ${ }^{c}$ Guillaume Izzet ${ }^{b},{ }^{*}$ Elizabeth A. Gibson. ${ }^{a}$ *

${ }^{a}$ Energy Materials Laboratory, Chemistry: School of Natural and Environmental Science, Newcastle University, Newcastle upon Tyne, NE1 7RU, UK. Elizabeth.gibson@ncl.ac.uk, ORCID 0000-0002-6032-343X

${ }^{\mathrm{b}}$ Sorbonne Université, CNRS, Institut Parisien de Chimie Moléculaire, IPCM, 4 Place Jussieu, F-75005 Paris, France, E-mail: guillaume.izzet@sorbonne-universite.fr ORCID 0000-0002-9849-4939

'Department of Chemical Physics and NanoLund, Lund University, Box 124, 22241, Lund, Sweden. E-mail: Tonu.Pullerits@chemphys.lu.se ORCID 0000-0003-1428-5564

\begin{abstract}
$\mathrm{H}^{+}$modulated charge-transfer in photoexcited covalent polyoxometalate-bodipy conjugates is described. The hybrid organic/inorganic molecular photoactive dyads are based on Keggin-type polyoxometalates (POMs, where $\mathrm{K}^{\mathrm{M}}=\left[\mathrm{PM}_{11} \mathrm{O}_{39}\right]$ and $\mathrm{M}=\mathrm{Mo}$ or $\mathrm{W}$ ) covalently grafted via an organotin linker to a bodipy (BOD) photosensitizer. The relative potentials of the photosensitizer and POM are aligned such that lightinduced electron transfer from BOD to POM is permitted for the polyoxomolybdate $\mathbf{K}^{\mathrm{Mo}}{ }_{\text {Sn }}$ [BOD] but not effective for the polyoxotungstate analogue $\mathbf{K}_{{ }_{S n}}[$ [BOD]. In both cases, the addition of acid shifts the redox potential of the POM only, to increase the driving force for electron transfer. This leads to chargeseparation being switched on for $\mathbf{K}^{\mathrm{W}}{ }_{\text {sn }}[\mathrm{BO}]$ in the presence of acid. The addition of acid to $\mathbf{K}^{\mathrm{Mo}}{ }_{\text {sn }}$ [BOD] accelerates charge-separation by an order of magnitude (from 2 ns to 200 ps) and is accompanied by a deceleration of charge recombination, leading to a charge-separated state lifetime of up to $1.3 \mu \mathrm{s}$. This behaviour is consistent with proton coupled electron transfer, which has previously been observed electrochemically for POMs, but this study shows, for the first time, the impact of protonation on photoinduced electron transfers.
\end{abstract}

\section{Introduction}

Combined transfer of protons and electrons is key to energy conversion and storage, from photosynthesis to fuel cells. ${ }^{1-4}$ Proton-coupled electron transfer (PCET) is well known in photosystem II, which consumes, globally, four electrons and four protons in the water oxidation process. Investigation of PCET in biological and molecular model systems provides the basis of a general understanding of PCET processes. ${ }^{5}$ While molecular PCET reactions have been thoroughly investigated by electrochemical approaches, PCET 
reactions of electronically excited molecules have been explored somewhat less. ${ }^{6}$ Most photoactive, bioinspired, PCET dyad systems contain a phenolic unit as a proton/electron donor (mimicking the Tyrosine-Z of the Photosystem II, which plays a key role in the electron transport chain) and a light harvesting unit acting as an electron acceptor. ${ }^{2-4}$ By contrast, photoactive covalent dyads leading to photoinduced PCET oxidation of the photosensitizer have received much less attention. ${ }^{7}$ This drove us to study the behaviour of photosensitized polyoxometalate (POM)-based dyads (nanosized polyanionic molecular metal-oxo clusters) since POMs have well-known proton/electron reservoir properties. ${ }^{8,9}$ The redox properties of POMs are modified substantially in the presence of protons, as a consequence of counter-cation exchange and proton assistance in the reduction processes. Furthermore, the basicity of POMs substantially increases upon their reduction. ${ }^{10-12}$ Consequently these systems perform PCET in the presence of an acid source.

POMs have been used extensively in various photoredox reactions; however they typically absorb light in the UV region and, therefore, require a molecular photosensitizer. ${ }^{13-16}$ Modular POM-based hybrid systems, in which the polyoxometalate framework is covalently bound to a photosensitizer, offer opportunities to finely control charge-transfer through the tuneability of the electronic properties of the photosensitizer, bridge and POM subunits. ${ }^{13-15,17-20}$ Izzet, Artero and coll. showed that illumination of a hybrid based on Ir photosensitizer coupled to a Dawson polyoxotungstate led to charge accumulation at the POM and hydrogen evolution in the presence of a proton source and a sacrificial electron donor. More recently, Rau, Streb, Dietzek and coll. reported a series of iridium photosensitizer-anderson POM hybrids which also evolve $\mathrm{H}_{2}$, and the activity depends on the central transition metal ( $\mathrm{Mn}, \mathrm{Fe}, \mathrm{Co}$ ) and the type of bridge. ${ }^{21,22}$ Precious metal-free photosensitizers such as zinc porphyrin, perylene, pyrene and boron dipyrromethene (bodipy) have also been applied. ${ }^{13,14,17,23,24}$ In these systems, charge-transfer from the sensitizer to the POM occurs either through space or through the bridge, depending on the structure. ${ }^{25}$ In bodipy photosensitized POM conjugates, we previously showed that the occurrence and kinetics of photoinduced electron transfer was strongly dependant on the redox properties of both POM and the bodipy sensitizer. Notably the hybrid displaying the best electron accepting properties (i.e. organosilyl POM derivatives) led to very rapid ( $50 \mathrm{ps}$ ) charge injection upon the excitation of the photosensitizer unit. ${ }^{14,18,23}$

This new study focuses on two new Keggin organotin-bodipy (BOD) dyads, $\mathbf{K}^{\mathrm{w}}{ }_{\mathrm{Sn}}$ [BOD] and $\mathbf{K}^{\mathrm{Mo}}{ }_{\text {Sn }}$ [BOD]. Keggin organotin derivatives display higher negative charge and, hence, are weaker electron acceptors compared to the Keggin organosilyl derivatives. Consequently, one would expect, based on our previous studies, that these Keggin organotin-bodipy systems would be slower (both for charge separation and recombination) compared to the previous organosilyl POM-bodipy derivative, thus more prone to significant modification upon the addition of an acid source. 


\section{Results}

\section{Synthesis}

The hybrid (TBA) $)_{4}\left[\mathrm{PW}_{11} \mathrm{O}_{39}\left\{\mathrm{SnC}_{31} \mathrm{H}_{30} \mathrm{BF}_{2} \mathrm{~N}_{2}\right\}\right]$ and $(\mathrm{TBA})_{4}\left[\mathrm{PMO}_{11} \mathrm{O}_{39}\left\{\mathrm{SnC}_{31} \mathrm{H}_{30} \mathrm{BF}_{2} \mathrm{~N}_{2}\right\}\right]$ respectively named $\mathbf{K}^{\mathrm{W}}{ }_{\mathrm{Sn}}[\mathrm{BOD}]$ and $\mathbf{K}^{\mathrm{Mo}}{ }_{\mathrm{Sn}}[\mathrm{BOD}]$ are isocharge and isostructural (Scheme 1). They contain one bodipy unit connected to the mono-lacunary site of a Keggin $\left(\left[\mathrm{PM}_{11} \mathrm{O}_{39}\right]^{7-}\right)$ polyoxometalate. They differ by the nature of the metallic atom addenda of the POM (tungsten vs molybdenum). The main difference between both hybrids lies in their redox properties. The polyoxomolybdate is easier to reduce than the polyoxotungstate analogue (reduction potentials are shifted by $c a+0.5 \mathrm{~V}$ ). Furthermore, polyoxomolybdates are more sensitive to the addition of an acid source due to the higher basicity of their reduced forms compared to polyoxotungstates. ${ }^{10}$ The synthesis of the POM-bodipy hybrids was performed in one step from the iodoaryl terminated POM-based platform (named $\mathbf{K}^{\mathrm{W}}{ }_{{ }_{\mathrm{Sn}}}[\mathrm{I}]$ and $\mathbf{K}^{\mathrm{Mo}}{ }_{{ }_{\mathrm{Sn}}}[\mathrm{I}]$ ), by adapting our previously reported procedure involving a Sonogashira cross-coupling reaction. ${ }^{26}$ The hybrids were isolated as tetrabutyl ammonium (TBA) salts in good yield and characterized by multinuclear NMR spectroscopy, mass spectrometry, elemental analyses and FTIR spectroscopy (Figures S1-S4).
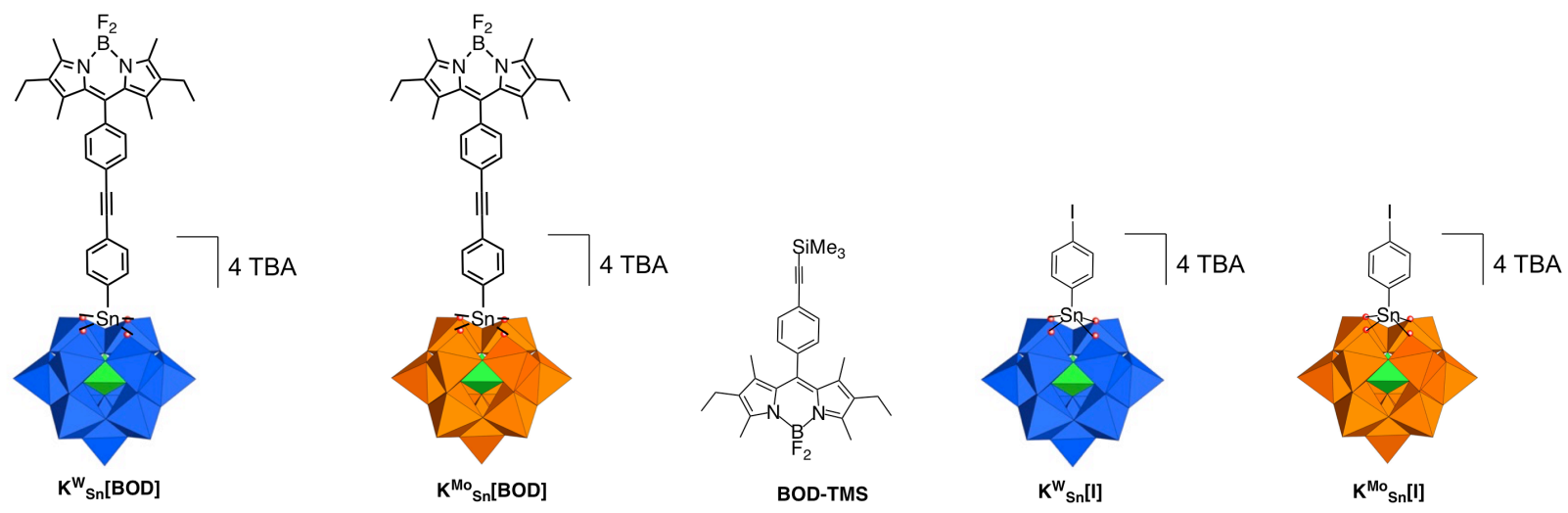

Scheme 1. Molecular schemes for the POM-bodipy conjugates described in this study $\left(\mathbf{K}^{\mathbf{W}}{ }_{{ }_{n}}\right.$ [BOD], $\left.\mathbf{K}^{\mathrm{Mo}}{ }_{\text {Sn }}[\mathrm{BOD}]\right)$, the bodipy reference compound BOD-TMS and the iodoaryl-terminated POM-based platforms $\left(\mathrm{K}^{\mathrm{W}}{ }_{\mathrm{Sn}}[\mathrm{I}], \mathrm{K}^{\mathrm{Mo}}{ }_{\mathrm{Sn}}[\mathrm{I}]\right)$. Color code: $\mathrm{WO}_{6}$ octahedra, blue; $\mathrm{MoO}_{6}$ octahedra, orange; $\mathrm{PO}_{4}$ tetrahedra, green.

\section{Optical and electrochemical properties}

The redox properties of the POM-bodipy dyads, their related POM hybrids and bodipy references were investigated by cyclic voltammetry in deoxygenated acetonitrile (MeCN) with tetrabutylammonium hexafluorophosphate $\left(\mathrm{TBAPF}_{6}\right.$ ) as the supporting electrolyte in a standard three-electrode cell, composed of a glassy carbon working electrode, a platinum counter electrode, and a saturated calomel reference electrode (SCE) (Fig. 1 and S5-S6 and Table 1). Surprisingly, though at a comparable potential, the oxidation processes of $\mathbf{K}^{\mathrm{W}}{ }_{S n}[\mathbf{B O D}]$ and $\mathbf{K}^{\mathrm{Mo}}{ }_{\text {Sn }}[\mathrm{BOD}]$ are irreversible while that of BOD-TMS and that of the previously reported organosilyl POM-bodipy are reversible. Yet, as expected, at negative applied potentials, the redox

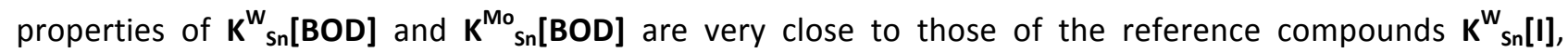


$\mathrm{K}^{\mathrm{Mo}}{ }_{\mathrm{Sn}}[\mathrm{I}]$ and BOD-TMS, which is consistent with our previously reported POM hybrids. ${ }^{14,}{ }^{27}$ At negative potentials, $\mathbf{K}^{\mathrm{w}}{ }_{\mathrm{Sn}}[\mathrm{BOD}]$ displays three quasi-reversible monoelectronic processes. The first and the third processes are attributed to the reduction of the POM framework while the second process corresponds to the reduction of the bodipy unit. In the cyclic voltammetry of $\mathbf{K}^{\mathrm{Mo}}{ }_{\mathrm{S}_{n}}[\mathrm{BOD}]$, the features are slightly more complex due to the richer redox behaviour of the polyoxomolybdate framework relative to its tungstate analogue. Five reduction processes are present, the first three are monoelectronic reductions of the POM framework (one quasi reversible followed by two non-reversible processes), followed by a quasi-reversible process at $-1.21 \mathrm{~V}$ vs SCE attributed to the overlapping one-electron reductions of the bodipy and of the three-electron reduced POM.

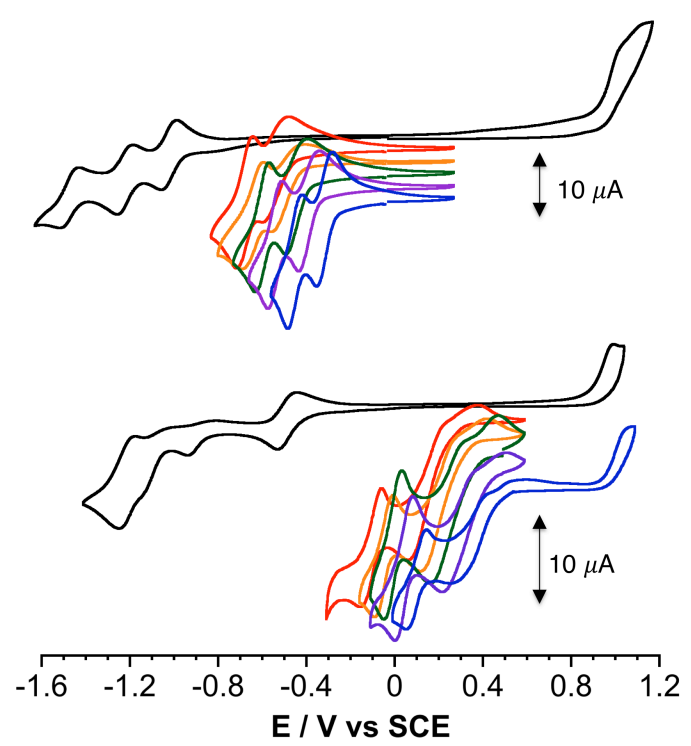

Figure 1. Cyclic voltammograms of $\mathbf{K}^{\mathrm{W}}{ }_{\mathrm{Sn}}$ [BOD] (black curve, top panel, scan rate $20 \mathrm{mV} \mathrm{s}^{-1}$ ) and $\mathbf{K}^{\mathrm{Mo}}{ }_{\mathrm{sn}}$ [BOD] (black curve, lower panel, scan rate $10 \mathrm{mV} \mathrm{s}^{-1}$ ) $1 \mathrm{mM}$ in MeCN containing $0.1 \mathrm{M} \mathrm{TBAPF}_{6}$ solutions and after the addition of 30 (red), 60 (orange), 100 (green), 200 (purple) and 500 (blue) equiv. of trifluoroacetic acid (TFA) ; working electrode, glassy carbon; reference electrode, SCE.

Table 1. Half-wave potential (vs SCE, in V) and peak-to-peak separation ( $\mathrm{mV}$ ) of the redox processes for the reported hybrids and reference compounds in acetonitrile containing $0.1 \mathrm{M} \mathrm{TBAPF}_{6}$. In the case of an irreversible process, the potential is not given.

\begin{tabular}{lllll} 
Compound & {$[\mathrm{BOD}]^{+} /[\mathrm{BOD}]$} & {$[\mathrm{BOD}] /[\mathrm{BOD}]^{-}$} & $\mathrm{POM} / \mathrm{POM}+1 \mathrm{e}$ & $\mathrm{POM}+1 \mathrm{e} / \mathrm{POM}+2 \mathrm{e}$ \\
\hline BOD-TMS & $1.02(80)$ & $-1.20(70)$ & $-1.46(70)$ \\
$\mathbf{K}_{\mathrm{Sn}}^{\mathrm{w}}[\mathrm{I}]$ & & $-0.99(70)$ & $-1.44(70)$ \\
$\mathbf{K}_{\mathrm{Sn}}^{\mathrm{w}}[\mathrm{BOD}]$ & $\mathrm{Irr}$ & $-1.19(70)$ & $-0.99(70)$ & $-0.90(\mathrm{irr})$ \\
$\mathbf{K}_{\mathrm{Sn}}^{\mathrm{Mo}}[\mathrm{l}]$ & & & $-0.47(90)$ & $-0.95(\mathrm{irr})$ \\
$\mathbf{K}_{\mathrm{Sn}}^{\mathrm{Mo}}[\mathrm{BOD}]$ & $\mathrm{Irr}$ & $-1.21(70)$ & $-0.48(90)$ & \\
\hline
\end{tabular}


The successive addition of trifluoroacetic acid (TFA, pKa $(\mathrm{MeCN})=12.65$, $\left.^{\text {pKauto }}(\mathrm{MecN})>33\right)^{28}$ up to 500 equiv.) to a solution of $\mathbf{K}^{\mathrm{w}}{ }_{\text {Sn }}$ [BOD] leads to a steady, positive shift of the reduction potentials as well as an increase in intensity due to multi-electron redox processes (Fig. 1, top). Two reversible waves corresponding to bielectronic reductions of the POM were observed, followed by the electrocatalytic reduction of the protons. This behaviour, is the same as that of organotin Keggin-type hybrids in the presence of TFA: ${ }^{27}$ upon addition of an acid the second one-electron wave progressively overlap with the first one-electron wave owing to the protonation of the reduced forms and the higher basicity of the twoelectron reduced species than that of the one-electron reduced species, in agreement with the classical behaviour of Kegging-type polyoxotungstates and polyoxomolybdates in acidified solvents. ${ }^{10-12,29,30}$ Consequently, only the potential for the for the reversible simultaneous bielectronic processes (which does not correspond exactly to the one-electron redox potential) can be determined. The values are listed in Table 2.

The effect of the protonation of $\mathbf{K}^{\mathrm{Mo}}{ }_{\text {Sn }}[\mathrm{BOD}]$ was also investigated, but ill-defined signals were observed. The best resolved waves were obtained at a scan rate of $10 \mathrm{mV} \mathrm{s}^{-1}$, revealing two closely-positioned bielectronic reduction processes, followed by a quasi-reversible bielectronic reduction of the POM. We previously showed that the organic and inorganic moieties in these hybrids are electronically decoupled. ${ }^{16,24,27}$ Consequently, we studied the behaviour of the parent polyoxomolybdate $\mathbf{K}^{\mathrm{Mo}}{ }_{\text {sn }}[\mathbf{l}]$ as a model system to evaluate the redox potential of the polyoxomolybdate core upon the addition of TFA. With $\mathbf{K}^{\mathrm{Mo}}{ }_{\mathrm{Sn}}[\mathrm{I}]$ we could observe up to 5 reversible bielectronic processes (Fig. S6). Control over the quantity of added protons thus allows the first reduction potential of the POM to be tuned within a potential window of $-0.99 \mathrm{~V}$ to $-0.29 \mathrm{~V}$ vs. SCE and -0.48 to $0.51 \mathrm{~V}$ vs. SCE for $\mathbf{K}^{\mathrm{W}}{ }_{\text {Sn }}[\mathrm{BOD}]$ and $\mathbf{K}^{\mathrm{Mo}}{ }_{\text {Sn }}[1]$, respectively.

Table 2. Half-wave potentials ( $\mathrm{V}$ vs. SCE) and peak-to-peak separation $(\mathrm{mV})^{\mathrm{a}}$ of $\mathbf{K}^{\mathrm{W}}{ }_{\mathrm{Sn}}[\mathrm{BOD}]$ and $\mathbf{K}^{\mathrm{Mo}}{ }_{{ }_{\mathrm{Sn}}}[\mathrm{l}]$ (reference compound of $\left.\mathbf{K}^{\mathrm{Mo}}{ }_{\mathrm{Sn}}[\mathrm{BOD}]\right) 1 \mathrm{mM}$ in MeCN upon the addition of TFA.

\begin{tabular}{|c|c|c|c|c|}
\hline \multirow{2}{*}{ TFA (eq. / POM) } & \multicolumn{2}{|c|}{$\mathrm{K}_{\mathrm{Sn}}^{\mathrm{W}}[\mathrm{BOD}]$} & \multicolumn{2}{|c|}{$\mathrm{K}^{\mathrm{Mo}}{ }_{\mathrm{Sn}}[\mathrm{I}]$} \\
\hline & $E_{1 / 2,1}$ & $\mathrm{E}_{1 / 2,2}$ & $\mathrm{E}_{1 / 2,1}$ & $\mathrm{E}_{1 / 2,2}$ \\
\hline 30 & -0.50 (n.c.) & -0.64 (n.c.) & 0.28 (n.c.) & 0.20 (n.c.) \\
\hline 60 & -0.45 (n.c.) & -0.61 (n.c.) & 0.32 (n.c.) & 0.25 (n.c.) \\
\hline 100 & $-0.41(100)$ & $-0.57(60)$ & 0.36 (n.c.) & 0.28 (n.c.) \\
\hline 200 & $-0.36(95)$ & $-0.51(65)$ & $0.42(80)$ & $0.33(60)$ \\
\hline 500 & $-0.29(70)$ & $-0.42(65)$ & $0.51(65)$ & $0.40(60)$ \\
\hline
\end{tabular}

\footnotetext{
${ }^{\mathrm{a}}$ The peak-to-peak separation is only given when the peaks were clearly resolved. n.c.: non-calculable.
} 
The electronic absorption spectra for bodipy reference compounds and POM-bodipy hybrids dissolved in $\mathrm{MeCN}$ are shown in Fig. 2. In the visible range, the absorption spectra of the hybrids are dominated by the bodipy absorption since the POM itself only absorbs in the UV part. The absorption profiles show the typical bodipy-centred $\mathrm{S}_{0}-\mathrm{S}_{1}$ absorption with a maximum at $523 \mathrm{~nm}$ in both hybrids and the BOD-TMS. The absence of a shift in absorption maximum between the BOD-TMS and the hybrids indicates that there is no apparent electronic coupling between the chromophore and the electron acceptor in the ground state. This is consistent with the related $\mathbf{K}^{\mathrm{W}}{ }_{\text {si }}[\mathrm{BOD}]$ hybrid that we previously reported and corresponds to the classical behavior of these series of organosilyl and organotin derivatives of POMs. ${ }^{27}$ The emission of the hybrids displays similar profiles, yet with different relative quantum yields. While the fluorescence intensity of $\mathbf{K}^{\mathrm{W}}{ }_{\mathrm{Sn}}$ [BOD] is close to that of BOD-TMS, it is considerably less intense (by ca. $55 \%$ ) in the case of $\mathbf{K}^{\mathrm{Mo}}{ }_{\mathrm{Sn}}[\mathrm{BOD}]$, suggesting that light-induced charge transfer occurs from the bodipy to the $\mathbf{K}^{\mathrm{Mo}}{ }_{\mathrm{Sn}}$ POM. While the addition of TFA on BOD-TMS (500 equiv.) has no effect on its fluorescence, it is not the case for $\mathbf{K}^{\mathrm{W}}{ }_{\text {Sn }}$ [BOD] and $\mathbf{K}_{\text {Sn }}^{\mathrm{Mo}}$ [BOD] (Fig. S7), in which the emission is quenched by $c a .40 \%$ and $85 \%$ respectively upon the addition of 500 equiv. TFA (Table S1).

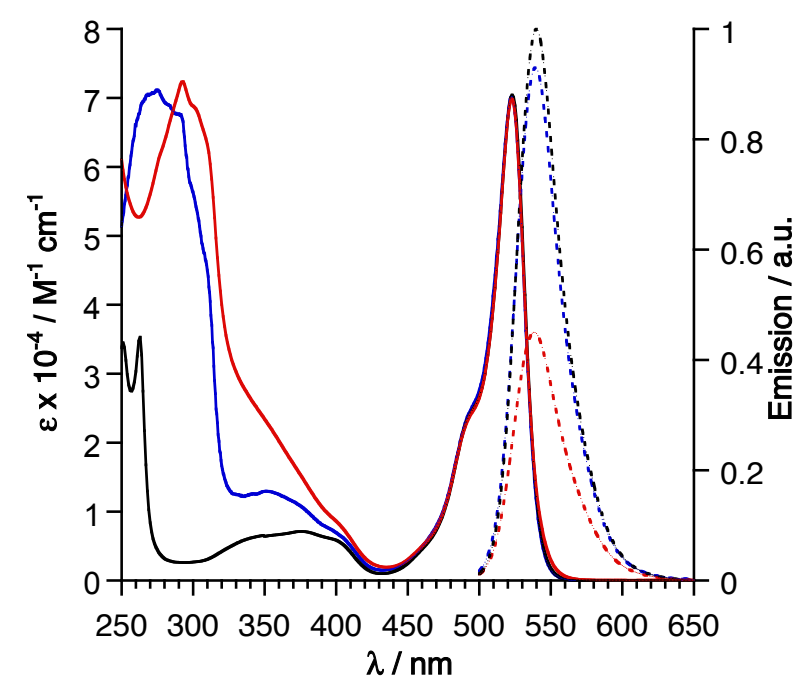

Figure 2. UV-visible absorption and normalized emission spectra (dashed line, divided by the emission maximum of BOD-TMS) of $\mathbf{K}^{\mathrm{w}}{ }_{{ }_{n}}[\mathrm{BOD}]$ (blue), $\mathbf{K}^{\mathrm{Mo}}{ }_{\mathrm{Sn}}[\mathrm{BOD}]$ (red) and the bodipy reference compound BODTMS.

\section{Transient absorption spectroscopy in organic solvent}

Transient absorption (TA) spectroscopy was performed on $\mathrm{N}_{2}$-purged MeCN solutions of $\mathbf{K}^{\mathrm{w}_{\text {sn }}}$ [BOD] and $\mathbf{K}^{\mathrm{Mo}}{ }_{\text {Sn }}[\mathrm{BOD}]$ and the results are displayed in Figure 3. The shape (broad absorption centred at approximately $440 \mathrm{~nm}$ ) and lifetime $(\tau=4.1 \mathrm{~ns})$ of the transient spectra for $\mathbf{K}^{\mathrm{w}}{ }_{\mathrm{Sn}}$ [BOD] are consistent with decay of the singlet excited state of the bodipy $\left(S_{1}\right)$. The ground state bleach at $520 \mathrm{~nm}$ is accompanied by a negative signal from stimulated emission between $550-700 \mathrm{~nm}$. The presence of this single component indicates that 
the charge-separated state is not formed, which is consistent with the electrochemical data above. Indeed, the thermodynamic driving force of the electron transfer from the excited BOD unit to the POM core, which can be estimated from the Rehm-Weller equation, ${ }^{31,32}$ is modest $\left(\Delta \mathrm{G}_{\mathrm{CS}}=-0.35 \mathrm{eV}, \mathrm{E}_{0-0}\right.$ and the electrostatic work term are estimated to be $2.34 \mathrm{eV}$ and $0.02 \mathrm{eV}$ respectively). ${ }^{33}$

$\Delta G_{C S}=E\left(B O D / B^{+} D^{+}\right)-E(P O M / P O M-)-E_{O O}+W_{e l}$

In contrast, the transient spectra for $\mathbf{K}^{\mathrm{Mo}}{ }_{\text {sn }}[\mathrm{BOD}]$ in $\mathrm{MeCN}$ (Fig. 3 (b)-(c)) evolve over time. The first of two transients has the same general shape for the $\mathrm{S}_{1}$ state as $\mathrm{K}^{\mathrm{wn}}{ }_{{ }_{\mathrm{n}}}[\mathrm{BOD}]$ in $\mathrm{MeCN}$, which is consistent with the formation of the bodipy excited state. This decays with a lifetime of $\tau_{1}=2.2 \mathrm{~ns}$ (Fig. 3 (d)) concurrent with the formation of a second transient centred at $406 \mathrm{~nm}$, with a clear isosbestic point at $\lambda=c a .420 \mathrm{~nm}$. A broad absorption extending from $550 \mathrm{~nm}$ past $900 \mathrm{~nm}$, also grows over the same timescale. The shape and position of this second transient is consistent with that of both the oxidised bodipy ( $406 \mathrm{~nm}$ ) and reduced POM (550-900 nm), which we reported previously. ${ }^{14}$ This is clear evidence for the formation of a chargeseparated state, $\left[\mathrm{BOD}^{+}-\mathrm{POM}\left(+1 \mathrm{e}^{-}\right)\right]$. The result for $\mathbf{K}^{\mathrm{Mo}}{ }_{\mathrm{Sn}}[\mathrm{BOD}]$ is consistent with the electrochemical data, which indicate that electron transfer from the BOD to the polyoxomolybdate core is more thermodynamically favourable $\left(\Delta \mathrm{G}_{\mathrm{CS}}=-0.86 \mathrm{eV}\right)$. The second transient did not significantly decay during the $10 \mathrm{~ns}$ window of the ultrafast laser system and so a nanosecond flash photolysis system was employed to monitor the charge-recombination process, and the results are shown in Figure 3 (c). The lifetime of the charge-separated state was $\tau_{2}=16 \mathrm{~ns}$. 

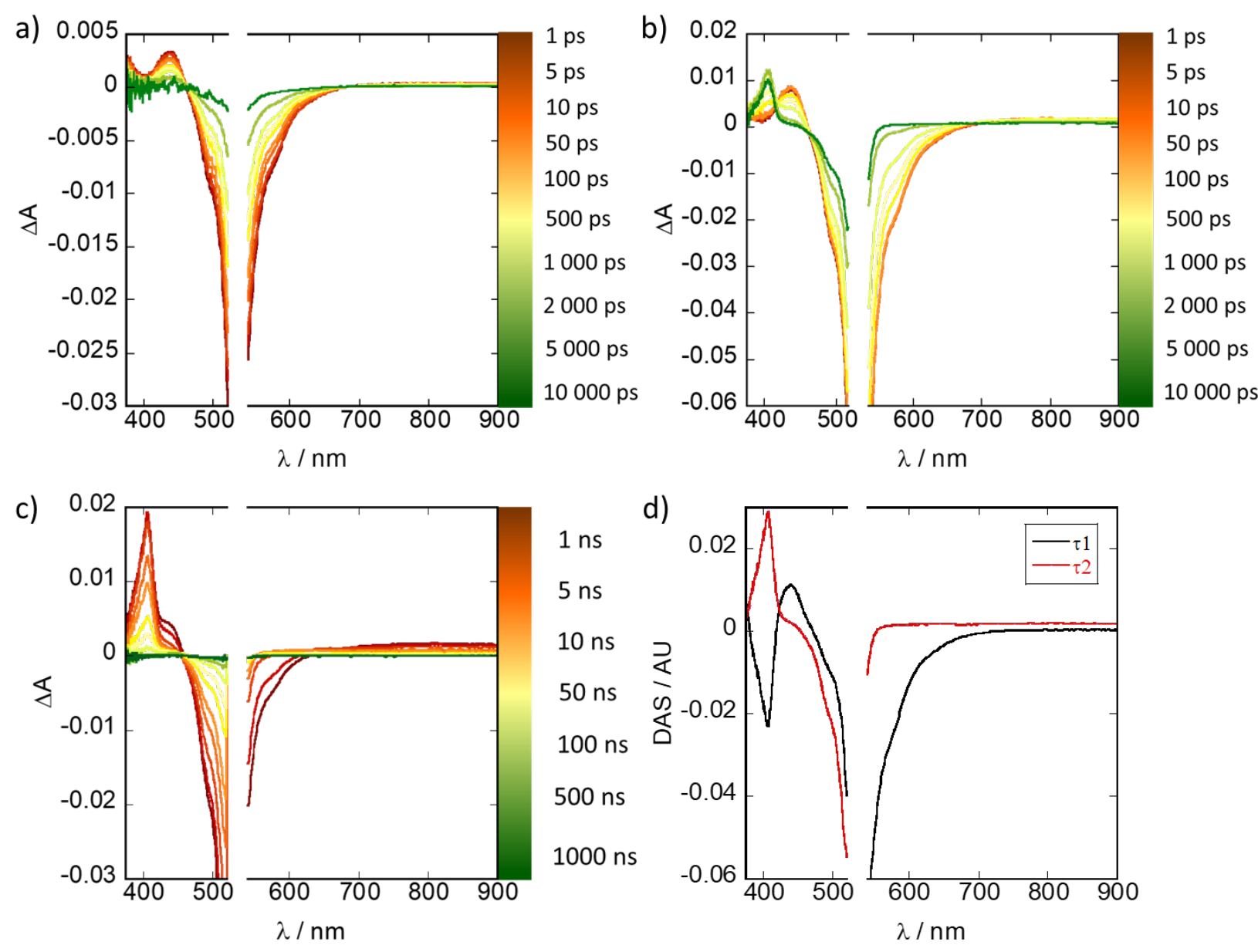

Figure 3. Transient absorption spectra of $\mathbf{K}^{\mathrm{W}}{ }_{\mathrm{Sn}}[\mathrm{BOD}]$ and $\mathbf{K}^{\mathrm{Mo}}{ }_{\mathrm{Sn}}[\mathrm{BOD}]$ in $\mathrm{MeCN}$ : (a) difference spectra for $\mathbf{K}^{\mathrm{Wn}}$ [BOD] at selected time delays after excitation at $540 \mathrm{~nm}$; (b) difference spectra at selected time delays after excitation at $540 \mathrm{~nm}$ for $\mathbf{K}^{\mathrm{Mo}}{ }_{\text {Sn }}$ [BOD] at early times; (c) transient absorption difference spectra at selected time delays after excitation at $532 \mathrm{~nm}$ for $\mathbf{K}^{\mathrm{Mo}}{ }_{{ }_{\mathrm{S}}}[\mathrm{BOD}]$ at longer times; (d) decay associated difference spectra (DAS) for $\mathbf{K}^{\mathrm{Mo}}{ }_{\mathrm{Sn}}[\mathrm{BOD}] . \boldsymbol{\tau}_{\mathbf{1}}$ corresponds to the bodipy-centred excited state (2.2 ns), $\boldsymbol{\tau}_{2}$ corresponds to the charge-separated state (16 ns).

The results are consistent with our previous study of an organosilyl POM-bodipy derivative $\mathbf{K}^{\mathrm{W}}{ }_{\mathrm{Si}}$ [BOD]. In the latter compound, electron transfer from the bodipy $S_{1}$ to the POM was very efficient $\left(\tau_{c s}=38\right.$ ps) in $\mathrm{MeCN}{ }^{23}$ The organotin derivatives display higher negative charge compared to the organosilyl derivatives, and, consequently, electron transfer is less favourable for the $\mathbf{K}^{\mathbf{w}}{ }_{s n}$ [BOD]. The charge separation for $\mathbf{K}^{\mathrm{Mo}}{ }_{\mathrm{Sn}}[\mathbf{B O D}]$ is more favourable than $\mathbf{K}^{\mathrm{w}}{ }_{\mathrm{Sn}}[\mathrm{BOD}]$, but the driving force is less than that of $\mathbf{K}^{\mathrm{W}}{ }_{{ }_{\mathrm{S}}}[\mathrm{BOD}]\left(\Delta \mathrm{G}_{\mathrm{CS}}=-\right.$ $1.02 \mathrm{eV}$ in $\mathrm{MeCN})$. Therefore, the significantly slower rate of photoinduced electron transfer within $\mathrm{K}^{\mathrm{Mo}}{ }_{\mathrm{Sn}}[\mathrm{BOD}]$ compared to $\mathrm{K}^{\mathrm{W}}{ }_{\mathrm{si}}[\mathrm{BOD}]$ is attributed to a lower driving force and, potentially, weaker electronic coupling through the linker. 
Transient absorption spectroscopy in organic solvent on addition of $\left[\mathrm{H}^{+}\right]$

Knowing that the addition of $\mathrm{H}^{+}$enhances the electron reservoir properties of POM-based hybrids, positively shifting the first reduction potential by $c a .700 \mathrm{mV}$ for $\mathbf{K}^{\mathrm{W}}{ }_{{ }_{\mathrm{Sn}}}[\mathrm{BOD}]$ and $c a .1 \mathrm{~V}$ for $\mathbf{K}^{\mathrm{Mo}}{ }_{\text {Sn }}[\mathrm{BOD}]$, the effect on the photophysics of the addition of TFA to both hybrids was evaluated and the lifetimes are given in Tables 3 and $4 .{ }^{34}$ As expected, the spectral shape and lifetime ( $\tau=5.1 \mathrm{~ns}$ ) of BOD-TMS in the presence and in the absence of TFA (Fig. S8 and S9 respectively) were identical. In contrast, the photophysical behaviour of $\mathbf{K}^{\mathrm{W}}{ }_{\text {Sn }}$ [BOD] substantially changed in the presence of TFA (Fig. S10 and S11). The addition of 30 equivalents of TFA switched on the electron transfer process. The decay of the excited state over $\tau_{1}=2.3 \mathrm{~ns}$ was accompanied by the growth of a sharp absorption at $405 \mathrm{~nm}$ and a broad absorption extending past $700 \mathrm{~nm}$, consistent with the formation of oxidised bodipy and reduced POM as mentioned earlier. This is in agreement with the positive shift of the reduction potential of the $\mathrm{K}^{\mathrm{W}}{ }_{\mathrm{s}}$ core by $c a .+0.5 \mathrm{~V}$ upon the addition of TFA and the increase of the driving force for electron transfer from the excited BOD unit to the polyoxotungstate framework. The lifetime for charge separation for $\mathrm{K}^{\mathrm{w}}{ }_{\text {sn }}$ [BOD] in the presence of 30 equiv. TFA were similar in magnitude to those observed for $\mathbf{K}^{\mathrm{Mo}}{ }_{\mathrm{Sn}}[\mathrm{BOD}]$ in the absence of TFA, in agreement with the similar driving force $\left(\Delta \mathrm{G}_{\mathrm{cs}}=-0.84 \mathrm{eV}\right.$ for $\mathrm{K}_{\mathrm{sn}}^{\mathrm{w}}[\mathrm{BOD}]+30$ equiv. TFA). The decay of the charge-separated state was estimated to be $c a .8 \mathrm{~ns}$ (the value falls close to the limit of the two laser systems, which lowers the precision of these measurements). Both the charge-separation and charge-recombination lifetimes were hardly affected by the addition of further equivalents of TFA (Table 3). The ns TA revealed the presence of a third component, which grew concurrently with the depletion of the charge-separated state (Fig. S12). This component is assigned to the bodipy-centred triplet state, and the spectral profile is consistent with previous reports of triplet-bodipy. ${ }^{35,36}$ We also observed such a recombination via a triplet state, previously, in a related compound which had a similar driving force for charge recombination $\left(\Delta \mathrm{G}_{\mathrm{cr}}=\right.$ $-1.55 \mathrm{eV}) .^{14}$ The partial formation of a bodipy-centred triplet state provides a second relaxation pathway from the charge-separated state and makes it difficult to evaluate the charge recombination kinetics, even though the amplitude of the triplet-forming component is relatively small.

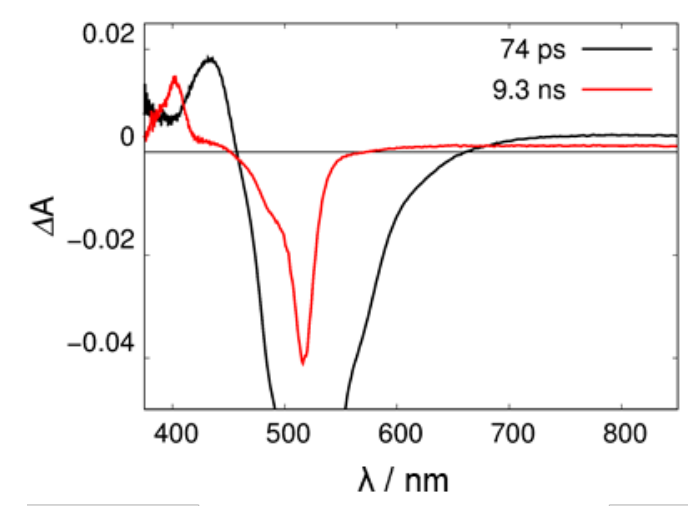


Figure 4. Transient absorption spectra of $\mathbf{K}^{\mathrm{w}}{ }_{\text {Sn }}$ [BOD] in MeCN on addition of 30 equivalents of TFA and excitation at $540 \mathrm{~nm}$; individual traces at time delays pertinent to the excited singlet (black - 74 ps) and charge separated state (red $-9.3 \mathrm{~ns}$ ).

Table 3. Transient lifetimes for $\mathbf{K}^{\mathbf{W}}{ }_{\text {Sn }}$ [BOD] in MeCN with additions of TFA. $\boldsymbol{\tau}_{1}$ corresponds to the excited state and was estimated by global analysis fitting of the fs-resolution transient absorption spectra, $\boldsymbol{\tau}_{2}$ corresponds to the chargeseparated state and was estimated by global fitting of the ns-resolution flash photolysis data.

\begin{tabular}{ccc}
\hline Equiv. TFA & $\boldsymbol{\tau}_{\mathbf{1}}$ (ns) & $\boldsymbol{\tau}_{\mathbf{2}}$ (ns) \\
\hline $\mathbf{0}$ & 4.1 & - \\
$\mathbf{3 0}$ & 2.3 & 8 \\
$\mathbf{6 0}$ & 2.4 & 9 \\
$\mathbf{1 0 0}$ & 2.4 & 11 \\
$\mathbf{2 0 0}$ & 2.6 & 30 \\
$\mathbf{5 0 0}$ & 2.7 & 36 \\
\hline
\end{tabular}

Table 4. Transient lifetimes for $\mathbf{K}^{\mathrm{Mo}}{ }_{\mathrm{Sn}}[\mathbf{B O D}]$ in MeCN with additions of TFA. $\boldsymbol{\tau}_{\mathbf{1}}$ corresponds to the excited state, $\boldsymbol{\tau}_{\mathbf{2}-\mathbf{3}}$ correspond to the charge-separated states. \% contributions estimated from the amplitude of the bleach.

\begin{tabular}{cccccccc}
\hline $\begin{array}{c}\text { Equiv. } \\
\text { TFA }\end{array}$ & $\boldsymbol{\tau}_{\mathbf{1}}$ (ps) & $\boldsymbol{\tau}_{\mathbf{2}}$ (ns) & $\%$ & $\boldsymbol{\tau}_{\mathbf{3}}(\mathrm{ns})$ & $\%$ & $\boldsymbol{\tau}_{\mathbf{4}}(\boldsymbol{\mu} \mathbf{s})$ & $\%$ \\
\hline $\mathbf{0}$ & 2200 & 16 & & & & \\
$\mathbf{3 0}$ & 180 & 32 & 66 & 890 & 34 & & \\
$\mathbf{6 0}$ & 140 & 31 & 59 & 920 & 41 & & \\
$\mathbf{1 0 0}$ & 100 & 32 & 48 & 980 & 52 & & \\
$\mathbf{2 0 0}$ & 84 & 32 & 63 & 1020 & 28 & 190 & 9 \\
$\mathbf{5 0 0}$ & 91 & 28 & 38 & 1300 & 62 & & \\
\hline
\end{tabular}

We repeated the experiment with $\mathbf{K}^{\mathrm{Mo}}{ }_{\mathrm{Sn}_{\mathbf{n}}}[\mathbf{B O D}]$. The transient spectra of $\mathbf{K}^{\mathbf{M o}}{ }_{\mathbf{S n}}[\mathbf{B O D}]$ in the presence of 30 equivalents of TFA are presented in Figures S13 and S14, the decay associated spectra are provided in Figure S15, and the impact of TFA concentration on the lifetime of formation and decay of the chargeseparated state is shown in Table 4. The spectral shape did not change with the addition of TFA. However, a remarkable acceleration of the rate of electron transfer from the excited BOD to the polyoxomolybdate core was observed, which was consistent with the relative change in the emission yield. With just 30 equivalents of TFA, the lifetime associated with charge-separation was 10 times shorter $\left(\tau_{1}=184\right.$ ps) with respect to $\mathbf{K}_{\text {Mn }}^{\mathrm{Mo}}[\mathbf{B O D}]$ in the absence of acid. An effect was also observed on the charge recombination. The global fit of the ns TA requires two decay components $\left(\tau_{2}=32 \mathrm{~ns}, 66 \%\right.$ and $\left.\tau_{3}=885 \mathrm{~ns}, 34 \%\right)$ indicating slower charge recombination processes than in the absence of TFA. Upon the addition of further equivalents of TFA, charge-separation continues to accelerate. The $30 \mathrm{~ns}$ component was consistently observed to be independent of the acid concentration. The longer lifetime increased systematically up to 
1300 ns for 500 equivalents of TFA. There was no difference in the spectral shape of the two transients, with lifetimes $\tau_{2}$ and $\tau_{3}$, for $\mathbf{K}^{\mathrm{Mo}}{ }_{S n}[\mathrm{BOD}]$, suggesting that there are two species with the oxidised chromophore, $\mathbf{B O D}^{+}$, which recombine at different rates. The relative amplitudes are sensitive to $\left[\mathrm{H}^{+}\right]$, the weight of the slower component rising from $34 \%$ to $62 \%$ on increasing the equivalents of TFA from 30 to 500.

\section{Discussion}

We and others have previously shown that the redox potentials of POMs are very sensitive to the presence of acids. ${ }^{10,12,27,29,30}$ In particular, the behaviour of a series of polyoxotungstate and polyoxomolybdate Keggin anions (e.g. $\mathrm{X}^{\mathrm{n}+} \mathrm{M}_{12} \mathrm{O}_{40}{ }^{(10-n)-}$ ) in acidified acetonitrile solutions has previously been thoroughly studied. ${ }^{10,12,30,37}$ The authors concluded that i) POMs become more basic as they are sequentially reduced; ii) the reduced polyoxomolybdates have a considerably higher basicity than the corresponding polyoxotungstates because of the smaller ionic radius. For instance, in acetonitrile, the pKa of the oneelectron reduced forms of $\left[\mathrm{GeW}_{12} \mathrm{O}_{40}\right]^{4-}$ and $\left[\mathrm{GeMo}_{12} \mathrm{O}_{40}\right]^{4-}$ (displaying the same charge as $\mathbf{K}^{\mathrm{Wn}}{ }_{\text {SnOD }}[\mathrm{BO}$ and $\left.\mathbf{K}^{\mathrm{Mo}}{ }_{\mathrm{Sn}}[\mathrm{BOD}]\right)$ were estimated to be 14.2 and 21.1 respectively. ${ }^{10}$

Upon the addition of TFA to solutions of $\mathbf{K}^{\mathrm{w}}{ }_{\mathrm{Sn}}[\mathrm{BOD}]$, the lifetime of the bodipy-centred excited state decreases and a second component grows in with a spectral shape consistent with oxidised bodipy. The relative lifetimes of the excited state are consistent with the partial quenching of the bodipy fluorescence under the same conditions. At 500 equivalents of TFA the fluorescence is quenched by $40 \%$, which matches the relative amplitude of the component corresponding to the charge-separated state (estimated from the bleach) recorded with ultrafast transient absorption spectroscopy. Increasing the molar equivalents of TFA from 30 to 500 has a modest effect on the charge separation. The evaluation of the lifetime of the charge separated state was complicated for this system owing to the formation of a long-lived third transient, likely a bodipy-centred triplet excited state. We previously observed the presence of the triplet excited state in a related system, $\mathrm{K}^{\mathrm{Wn}}{ }_{\mathrm{Sn}}[\mathrm{BOD}]$, and we attribute its formation to the heavy atom effect of $\mathrm{W}^{14}$

The behaviour of $\mathbf{K}^{\mathrm{Mo}}{ }_{{ }_{\mathrm{S}}}[\mathrm{BOD}]$ on the addition of TFA was quite different from $\mathbf{K}_{\mathrm{sn}_{n}}$ [BOD], and the addition of acid substantially increased the rate of charge separation. This suggests that, although charge separation occurs in the absence of TFA, the driving force $\left(\Delta G_{c s}=c a .-0.86 \mathrm{eV}\right)$ is not enough to permit efficient electron transfer. The slow electron transfer $(\tau=2.2 \mathrm{~ns})$ compared to the previous organosilyl system is attributed to a weaker driving force and also possibly to the weak electronic coupling via the anchoring tin atom. In the presence of TFA the driving force is doubled and the increase in rate of charge-separation is consistent with the increased quenching of the bodipy fluorescence. The effect of $\mathrm{H}^{+}$on the lifetime of the 
excited state indicates that protonation of the POM makes charge-separation thermodynamically more favourable and the addition of $\mathrm{H}^{+}$is not expected to alter the reorganisation energy significantly. The driving force for electron transfer from the photoexcited dye to the POM is estimated to rise from $\Delta G_{C S}=-$ $1.54 \mathrm{eV}$ to $-1.74 \mathrm{eV}$ for 30 to 500 equivalents of TFA, which should be in the Marcus inverted region. However, the inverted region for processes involving nuclear motion, such as $\mathrm{H}^{+}$transfer, is rarely observed experimentally because of the involvement of excited vibronic states, so these results are consistent with PCET. ${ }^{38-40}$ The rate of charge recombination for $\mathbf{K}^{\mathrm{Mo}}{ }_{\text {Sn }}[\mathrm{BOD}]$ was also affected by the amount of added TFA. The lifetimes of the charge-separated state doubled from $\tau_{2}=16 \mathrm{~ns}$ to $32 \mathrm{~ns}$ on the addition of 30 equivalents of TFA and a longer-lived component appeared which increased from $\tau_{3}=885 \mathrm{~ns}$ to $1300 \mathrm{~ns}$ when the TFA amount was increased from 30 equivalents to 500 equivalents. The increase in lifetime could be due to a stabilisation of the charge separated state by the further increase of TFA and a lower driving force for charge recombination $\left(\Delta \mathrm{G}_{\mathrm{CR}}=c a .-0.51\right.$ to $\left.-0.74 \mathrm{eV}\right)$, which falls in the Marcus normal region for electron transfer. In this system we observed no additional signal arising from the triplet excited state as we did with $\mathbf{K}_{\text {sn }}{ }$ [BOD]. The modest driving force for the charge recombination appears to explain the longer lifetime of the charge-separated state. The origin of the very long-lived charge separated state $\left(\tau_{3}\right)$ could arise from different protonation states of the reduced POM, since the reduced POMs are known to be more basic than the oxidised forms. ${ }^{11}$ Alternatively, one cannot rule out bimolecular processes as it is well known that in the presence of acid mono-reduced POMs disproportionate, ${ }^{41}$ leading to the formation of $\mathrm{BOD}^{+}-\mathrm{POM}$ and $\mathrm{BOD}-\mathrm{POM}\left(+1 \mathrm{e}^{-}\right) / \mathrm{H}^{+}$according to the following equation.

$2 \mathrm{BOD}^{+}-\mathrm{POM}\left(+1 \mathrm{e}^{-}\right) / \mathrm{H}^{+} \rightarrow \mathrm{BOD}^{+}-\mathrm{POM}+\mathrm{BOD}^{+}-\mathrm{POM}\left(+2 \mathrm{e}^{-}\right) / 2 \mathrm{H}^{+} \rightarrow \mathrm{BOD}^{+}-\mathrm{POM}+\mathrm{BOD}-\mathrm{POM}\left(+1 \mathrm{e}^{-}\right) / 1 \mathrm{H}^{+}+1 \mathrm{H}^{+}$

Subsequent recombination would be limited by the diffusion of the species in solution. From an application perspective, the remarkable increase in the lifetime of the charge separated state in $\mathbf{K}^{\mathrm{Mn}}{ }_{\mathrm{Sn}}$ [BOD] largely compensate the diminution of its reducing power. 


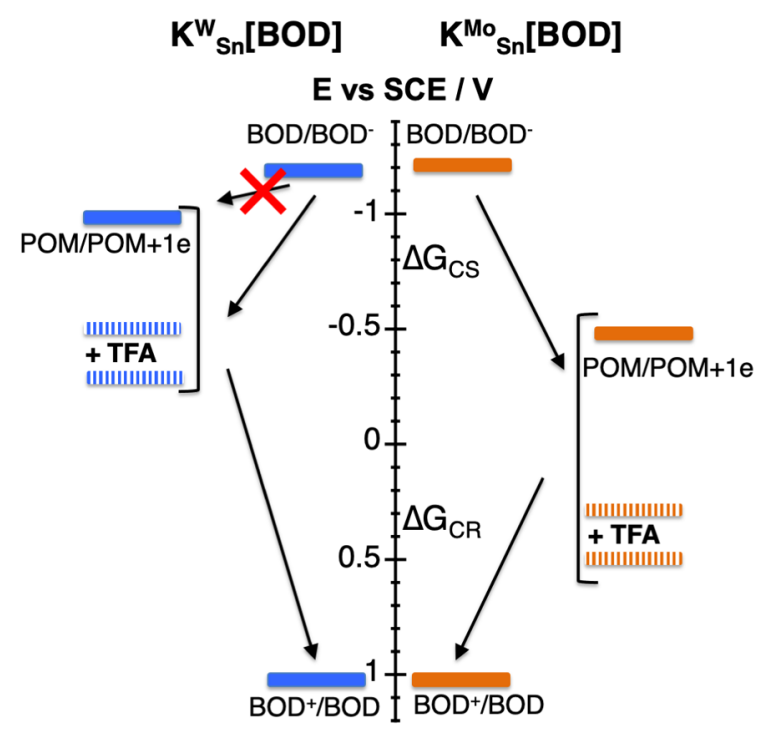

Figure 5. Energy level diagram of the POM-bodipy hybrids $\mathbf{K}^{\mathrm{W}}{ }_{\mathrm{Sn}}[\mathrm{BOD}]$ and $\mathbf{K}^{\mathrm{Mo}}{ }_{\mathrm{Sn}}[\mathrm{BOD}]$ showing the effect of in the presence of TFA in MeCN.

We have shown that photoinduced electron transfer in $\mathbf{K}^{\mathrm{W}}{ }_{\mathrm{Sn}}[\mathrm{BOD}]$ and $\mathbf{K}^{\mathrm{Mo}}{ }_{\mathrm{Sn}}[\mathrm{BOD}]$ can be triggered or greatly accelerated in the presence of TFA. To establish the mechanism, we need to account for the effect of the proton on the relaxation dynamics of the excited states. This is not possible to achieve from solely the electrochemical potentials, which are derived at thermodynamic equilibrium, together with the nonequilibrium, excited state, relaxation dynamics. For example, while the gradual addition of TFA continuously shifts the bielectronic reduction waves of $\mathbf{K}_{{ }_{S n}}$ [BOD], increasing the molar equivalents of TFA from 30 to 500 has a modest effect on the rate of charge separation. As mentioned previously, it has been reported that reduced forms of polyoxotungstate and polyoxomolybdate Keggin anions are easier to protonate than the oxidised forms. Increasing amounts of TFA change the ${ }^{31} \mathrm{P} N M R$ chemical shift of the POM (Figure S16), showing that there is some interaction between $\mathrm{H}^{+}$and the oxidized forms of the hybrids. The effect is stronger with polyoxomolybdate than with polyoxotungstate, in agreement with the stronger basicity of polyoxomolybdate. However, in both cases the interaction is weak and full protonation is unlikely in the presence of 30 equiv. TFA because further addition of acid leads to a further gradual shift in both redox potential and fluorescence quenching. The weak basicity of the oxidized forms of POMs adds complexity to the analysis of the PCET in this system. Based on the short lifetime of the bodipy excited state in $\mathbf{K}^{\mathrm{Mo}}{ }_{\mathrm{Sn}}[\mathrm{BOD}](\tau=180 \mathrm{ps}$ to $90 \mathrm{ps}$ ), it is more likely that sequential proton transfer followed by electron transfer takes place rather than concerted PCET. For charge recombination, it is unlikely that the proton transfer would occur first owing to the strong basicity of the one-electron reduced POM, so charge recombination most likely occurs following a sequential electron transfer followed by a proton transfer or a concerted mechanism, and this process may be bimolecular. Theoretical investigations, 
considering the energy of the different states according to the POM-proton distance should provide important insights into the concerted vs sequential nature of the PCET in these model systems.

\section{Conclusions}

We have shown that for $\mathbf{K}^{\mathrm{Mo}}{ }_{\mathrm{Sn}}[\mathrm{BOD}]$ photoinduced electron transfer occurs in the absence of a proton source, while for $\mathbf{K}^{\mathrm{W}}{ }_{s_{n}}[\mathbf{B O D}]$ the driving force of the electron transfer is not sufficient without an acid. After the addition of TFA both POM redox potentials were shifted to more positive values (as classically reported with POMs), making electron transfer from bodipy to polyoxotungstate more favourable. For $\mathbf{K}^{\mathrm{w}}{ }_{\mathrm{sn}}$ [BOD], electron transfer is partially switched on when TFA molecules are present. Yet in this compound, the driving force of the charge separation, even in the presence of TFA is not sufficient to promote efficient charge separation to the POM. Furthermore in this compound, charge recombination is more rapid than the molybdate system, with a noticeable portion of bodipy triplet being generated. The effect of TFA addition was more marked for $\mathbf{K}^{\mathrm{Mo}}{ }_{\mathrm{Sn}}[\mathrm{BOD}]$ : the photoinduced charge separation becomes increasingly fast while charge recombination becomes slower, reaching a plateau at 500 eq. of trifluoroacetic acid added, 91 ps and $1.3 \mu$ s respectively. It is worth mentioning that such a long-lived charge-separated (CS) state, makes $\mathbf{K}^{\mathrm{Mo}}{ }_{\mathrm{Sn}}[\mathrm{BOD}]$ appropriate for applications in photoelectrochemical devices, albeit with some loss in reduction potential. While the proton dependence of POMs redox properties is well established, this work demonstrates for the first time that this dependence can be used to finely tune the kinetics of electron transfer reactions of electronically excited molecules.

\section{Acknowledgements}

EAG, JK and EB thank The North East Centre for Energy Materials EP/R021503/1, ERC starting grant, p-TYPE 715354 and LaserLab Europe LLC002553. GI, AP, SB and YB M'B thank the French National Research Agency for Grant ANR PhotoCarb (ANR-16-CE05-0025- 03) TP and PC acknowledge financial support from the Swedish Energy Agency, Crafoord Foundation and the Swedish Research Council.

\section{Author contributions.}

$E B, J K$ and PC carried out the transient absorption spectroscopy, analysed the results and co-wrote the manuscript. TP and EG designed the transient absorption spectroscopy studies, interpreted the data and co-wrote the manuscript. YB M'B and SA synthesised and characterised the molecular systems and cowrote the manuscript. GI, SB and AP and, designed the molecular systems, interpreted the data and cowrote the manuscript.

\section{Additional Information}




\section{Supplementary information}

Experimental methods, synthesis and characterisation of $\mathbf{K}^{\mathrm{w}}{ }_{\mathrm{Sn}}[\mathrm{BOD}]$ and $\mathbf{K}^{\mathrm{Mo}}{ }_{\mathrm{Sn}}[\mathrm{BOD}]$, cyclic voltammetry, photoluminescence, transient absorption spectra and fitting are provided.

\section{Data availability}

Source data for the transient absorption spectroscopy is available from data.ncl.ac.uk (https://doi.org/10.25405/data.ncl.c.4939428)

\section{References}

1. S. Hammes-Schiffer, Controlling Electrons and Protons through Theory: Molecular Electrocatalysts to Nanoparticles, Acc. Chem. Res., 2018, 51, 1975-1983.

2. T. F. Liu, M. Y. Guo, A. Orthaber, R. Lomoth, M. Lundberg, S. Ott and L. Hammarstrom, Accelerating proton-coupled electron transfer of metal hydrides in catalyst model reactions, Nat. Commun., 2018, 10, 881-887.

3. M. Kuss-Petermann, M. Orazietti, M. Neuburger, P. Hamm and O. S. Wenger, Intramolecular LightDriven Accumulation of Reduction Equivalents by Proton-Coupled Electron Transfer, J. Am. Chem. Soc., 2017, 139, 5225-5232.

4. S. J. Mora, E. Odella, G. F. Moore, D. Gust, T. A. Moore and A. L. Moore, Proton-Coupled Electron Transfer in Artificial Photosynthetic Systems, Acc. Chem. Res., 2018, 51, 445-453.

5. S. Hammes-Schiffer and A. A. Stuchebrukhov, Theory of Coupled Electron and Proton Transfer Reactions, Chem. Rev., 2010, 110, 6939-6960.

6. J. Bonin and M. Robert, Photoinduced Proton-Coupled Electron Transfers in Biorelevant Phenolic Systems, Photochem. Photobiol., 2011, 87, 1190-1203.

7. O. S. Wenger, Proton-Coupled Electron Transfer with Photoexcited Metal Complexes, Acc. Chem. Res., 2013, 46, 1517-1526.

8. J. J. Chen, M. D. Symes and L. Cronin, Highly reduced and protonated aqueous solutions of [P2W18062](6-) for on-demand hydrogen generation and energy storage, Nat. Commun., 2018, 10, $1042-1047$.

9. Y. Nishimoto, D. Yokogawa, H. Yoshikawa, K. Awaga and S. Irle, Super-Reduced Polyoxometalates: Excellent Molecular Cluster Battery Components and Semipermeable Molecular Capacitors, J. Am. Chem. Soc., 2014, 136, 9042-9052.

10. S. Himeno, M. Takamoto, R. Santo and A. Ichimura, Redox properties and basicity of Keggin-type polyoxometalate complexes, Bull. Chem. Soc. Jpn., 2005, 78, 95-100.

11. M. Sadakane and E. Steckhan, Electrochemical properties of polyoxometalates as electrocatalysts, Chem. Rev., 1998, 98, 219-237.

12. S. X. Guo, A. W. A. Mariotti, C. Schlipf, A. M. Bond and A. G. Wedd, A Systematic approach to the simulation of the voltammetric reduction of [alpha-SiW12040](4-) in buffered aqueous electrolyte media and acetonitrile, J. Electroanal. Chem., 2006, 591, 7-18.

13. B. Matt, C. Coudret, C. Viala, D. Jouvenot, F. Loiseau, G. Izzet and A. Proust, Elaboration of Covalently Linked Polyoxometalates with Ruthenium and Pyrene Chromophores and Characteriation of Their Photophysical Properties, Inorg. Chem., 2011, 50, 7761-7768.

14. F. A. Black, A. Jacquart, G. Toupalas, S. Alves, A. Proust, I. P. Clark, E. A. Gibson and G. Izzet, Rapid photoinduced charge injection into covalent polyoxometalate-bodipy conjugates, Chem. Sci., 2018, 9, 5578-5584.

15. B. Matt, J. Fize, J. Moussa, H. Amouri, A. Pereira, V. Artero, G. Izzet and A. Proust, Charge photoaccumulation and photocatalytic hydrogen evolution under visible light at an iridium(III)photosensitized polyoxotungstate, Energy Environ. Sci., 2013, 6, 1504-1508. 
16. C. Streb, New trends in polyoxometalate photoredox chemistry: From photosensitisation to water oxidation catalysis, Dalton Trans., 2012, 41, 1651-1659.

17. F. Odobel, M. Severac, Y. Pellegrin, E. Blart, C. Fosse, C. Cannizzo, C. R. Mayer, K. J. Eliott and A. Harriman, Coupled Sensitizer-Catalyst Dyads: Electron-Transfer Reactions in a Perylene-

Polyoxometalate Conjugate, Chem. Eur. J., 2009, 15, 3130-3138.

18. B. Matt, X. Xiang, A. L. Kaledin, N. N. Han, J. Moussa, H. Amouri, S. Alves, C. L. Hill, T. Q. Lian, D. G. Musaev, G. Izzet and A. Proust, Long lived charge separation in iridium(III)-photosensitized polyoxometalates: synthesis, photophysical and computational studies of organometallic-redox tunable oxide assemblies, Chem. Sci., 2013, 4, 1737-1745.

19. Y. S. Luo, M. Wachtler, K. Barthelmes, A. Winter, U. S. Schubert and B. Dietzek, Coexistence of distinct intramolecular electron transfer pathways in polyoxometalate based molecular triads, Phys. Chem. Chem. Phys., 2018, 20, 11740-11748.

20. Y. Luo, M. Wachtler, K. Barthelmes, A. Winter, U. S. Schubert and B. Dietzek, Direct detection of the photoinduced charge-separated state in a Ru(II) bis(terpyridine)polyoxometalate molecular dyad, Chem. Commun., 2018, 54, 2970-2973.

21. Y. Luo, S. Maloul, S. Schonweiz, M. Wachtler, C. Streb and B. Dietzek, Yield-not only Lifetime-of the Photoinduced Charge-Separated State in Iridium Complex-Polyoxometalate Dyads Impact Their Hydrogen Evolution Reactivity, Chem. Eur. J., 2020, 26, 8045-8052.

22. Y. S. Luo, S. Maloul, M. Wachtler, A. Winter, U. S. Schubert, C. Streb and B. Dietzek, Is electron pingpong limiting the catalytic hydrogen evolution activity in covalent photosensitizer-polyoxometalate dyads?, Chem. Commun., 2020, 56, 10485-10488.

23. G. Toupalas, J. Karlsson, F. A. Black, A. Masip-Sánchez, X. López, Y. Ben M'Barek, S. Blanchard, A. Proust, S. Alves, P. Chabera, I. P. Clark, T. Pullerits, J. M. Poblet, E. A. Gibson and G. Izzet, Tuning Photoinduced Electron Transfer in POM-bodipy Hybrids by Controlling the Environment; Experiment and Theory, Angew. Chem., Int. Ed., https://doi.org/10.1002/anie.202014677.

24. K. J. Elliott, A. Harriman, L. Le Pleux, Y. Pellegrin, E. Blart, C. R. Mayer and F. Odobel, A porphyrinpolyoxometallate bio-inspired mimic for artificial photosynthesis, Phys. Chem. Chem. Phys., 2009, 11, 8767-8773.

25. J. M. Cameron, D. J. Wales and G. N. Newton, Shining a light on the photo-sensitisation of organicinorganic hybrid polyoxometalates, Dalton Trans., 2018, 47, 5120-5136.

26. V. Duffort, R. Thouvenot, C. Afonso, G. Izzet and A. Proust, Straightforward synthesis of new polyoxometalate-based hybrids exemplified by the covalent bonding of a polypyridyl ligand, Chem. Commun., 2009, DOI: 10.1039/b913475a, 6062-6064.

27. G. Izzet, F. Volatron and A. Proust, Tailor-made Covalent Organic-Inorganic Polyoxometalate Hybrids: Versatile Platforms for the Elaboration of Functional Molecular Architectures, Chem. Rec., 2017, 17, 250-266.

28. J. T. Muckerman, J. H. Skone, M. Ning and Y. Wasada-Tsutsui, Toward the accurate calculation of pK(a) values in water and acetonitrile, Bba-Bioenergetics, 2013, 1827, 882-891.

29. C. Rinfray, S. Renaudineau, G. Izzet and A. Proust, A covalent polyoxomolybdate-based hybrid with remarkable electron reservoir properties, Chem. Commun., 2014, 50, 8575-8577.

30. T. Ueda, K. Kodani, H. Ota, M. Shiro, S. X. Guo, J. F. Boas and A. M. Bond, Voltammetric and Spectroscopic Studies of alpha- and beta-[PW12040](3-)Polyoxometalates in Neutral and Acidic Media: Structural Characterization as Their [(n-Bu4N)(3)][Pw(12)O(40)] Salts, Inorg. Chem., 2017, 56, 3990-4001.

31. D. Rehm and A. Weller, Kinetics And Mechanics Of Electron Transfer During Fluorescence Quenching In Acetonitrile, Ber. Bunsen-Ges. Phys. Chem., 1969, 73, 834-839.

32. D. Rehm and A. Weller, Kinetics Of Fluorescence Quenching By Electron And H-Atom Transfer, Isr. J. Chem., 1970, 8, 259-271.

33. $\mathrm{w}_{\mathrm{el}}=\mathrm{q} / 4 \pi \varepsilon_{0} \varepsilon_{\mathrm{s}} \mathrm{r}$. The POM-bodipy distance $\mathrm{r}$ is estimated to be ca. $2 \mathrm{~nm}$.

34. As it is difficult to determine precisely the first reduction potential in a bielectronic wave, for simplicity we have assimilated its value to the position of the bielectronic wave to estimate the driving force for the electron transfer reactions. 
35. Black, F. A. Probing Photoinduced Dynamics Within Dye-Sensitised Solar Cells. (Newcastle University, 2018).

36. J. F. Lefebvre, X. Z. Sun, J. A. Calladine, M. W. George and E. A. Gibson, Promoting chargeseparation in p-type dye-sensitized solar cells using bodipy, Chem. Commun., 2014, 50, 5258-5260.

37. B. Keita and L. Nadjo, New Aspects Of The Electrochemistry Of Heteropolyacids .4. Acidity Dependent Cyclic Voltammetric Behavior Of Phosphotungstic And Silicotungstic Heteropolyanions In Water And N,N-Dimethylformamide, J. Electroanal. Chem., 1987, 227, 77-98.

38. G. A. Parada, Z. K. Goldsmith, S. Kolmar, B. P. Rimgard, B. Q. Mercado, L. Hammarstrom, S. Hammes-Schiffer and J. M. Mayer, Concerted proton-electron transfer reactions in the Marcus inverted region, Science, 2019, 364, 471-475.

39. A. M. Kuznetsov and J. Ulstrup, Proton and proton-coupled electron transfer with paradigms towards single-molecule systems, J. Phys. Org. Chem., 2010, 23, 647-659.

40. S. J. Edwards, A. V. Soudackov and S. Hammes-Schiffer, Driving Force Dependence of Rates for Nonadiabatic Proton and Proton-Coupled Electron Transfer: Conditions for Inverted Region Behavior, J. Phys. Chem. B, 2009, 113, 14545-14548.

41. B. Keita and L. Nadjo, New Aspects Of The Electrochemistry Of Heteropolyacids .2. Coupled Electron And Proton Transfers In The Reduction Of Silicotungstic Species, J. Electroanal. Chem., 1987, 217, 287-304. 